\title{
Talking Music, Making Music: A Comparison Between Rap and Techno ${ }^{1}$
}

\author{
Antoine Hennion \\ MINES ParisTech, CSI - Centre de sociologie de l'innovation, CNRS UMR 7185, \\ antoine.hennion@mines-paristech.fr
}

The Ashgate Popular Musicology Research Companion, ch. 19 pp. 535-555

D. Scott ed., Ashgate, Hampshire, 2009

It's listeners who make music... ${ }^{2}$

This contribution, being work in progress, gathers together in an open fashion a body of reflections from a seminar given over to a comparison between rap and techno, and I begin with a brief reconsideration of common assumptions. This seminar was given with the object of studying listening, beginning with a series of juxtaposed experiments. ${ }^{3}$ The starting idea was simple: to regard music as being of an uncertain affect that depends on what its listener makes of it, and not as being an experience that is merely received. The word 'experiment' can, indeed, create confusion. It does not mean that we subjected guinea-pigs to regulated tests, in order to measure the best possible listener reactions to a given object. ${ }^{4}$ It would, of course, be one way of showing what music is. Moving in exactly the opposite direction, however, we have tried to make listeners the experts on their own listening, so that they can teach us what musical experience is for them.

The musical object is not already present, ready to undergo the various listenings that are directed towards it that we would then be able to measure. Even its immediacy is in question. Analyzing the musical moment is not a matter of measuring the way we hear various sounds. This would postulate music as already present, when the question is what makes it appear as such. It is not simply a matter of putting a CD in a CD player, and suddenly there is the music... That is why the cooperation of the listener in the definition of what happens is necessary.

In the first instance, one of our objectives is to benefit from the immense know-how that the listener deploys in seeking out preferences, managing pleasure, evaluating, testing, judging things at once, or delaying diagnoses. We wanted, with the listener's help, to test certain methods of accounting for all this. However, beyond this insider shrewdness, listeners have created a framework for their listening, having built their aural competencies over a long period of time. As much at the personal as at the collective level, ways of listening have a history (it is always necessary to think of listening as a plurality). They are not reducible to the vibration of a tympanum: they have been constructed through the

\footnotetext{
${ }^{1}$ Translated from the French original by Derek B. Scott.

2 To paraphrase Marcel Duchamp's famous 'Ce sont les regardeurs qui font les tableaux' (it's the viewers who make paintings).

${ }^{3}$ I am only the compiler of this essay; it would be more correct to speak of the collective work of participants of the CSI-School of Mines/CNRS seminar 'Aimer la musique. Musicologie du goût, sociologie de la musique, histoire de l'amateur', which I directed with J.-M. Fauquet (Antoine Hennion, 'L'Ecoute à la question', Revue de musicologie, 88/1 [2002]: 95-149). I thank in particular Morgan Jouvenet for the part on rap. An early French version of the present text appeared as 'Musiques, présentez-vous!', French Cultural Studies, 16/2 (2005): 121-34.

${ }^{4}$ It is not a question, either, of revealing that the social determinations of people's tastes are personal and subjective, in accordance with the familiar critical posture of the sociologist (Pierre Bourdieu, Distinction: A Social Critique of the Judgment of Taste [London, 1984]), nor of imagining a wild typology of listeners born of our own aesthetic conceptions, following the example of what Theodor Adorno does with as little scruple as talent ('Types d'attitude musicale', Introduction à la sociologie de la musique [Genève, 1994], pp. 7-25).
} 
invention of formats and repertoires, systems and arrangements, all of which have been debated by fans of various types of music in passionate discussion among themselves.

We also wanted the listener, this person little considered in musicology, to be given back a place in musical analyses. To the extent that, historically, the authorial regime came to occupy the centre ground of artistic creativity, studies of classical music became enthusiastically aligned in conformity with literary production. Instead of treating music as a complete object, they reduced it to the score alone, thus becoming at one and the same time an effect of and driving force behind the new subjugation of music to graphic reason. ${ }^{5}$ In passing, they had rid themselves of the listener, who was now handed over to the psychologist or acoustician. Some musicological work has certainly begun to take the listener back into account, ${ }^{6}$ but it would still be going too far to speak of the listener's uninterrupted presence in musical analyses. ${ }^{7}$

Listening is not, as many musicologists appear to believe, a means of accessing music by the back door. It is both an activity and a presence. The listener who participates in the production of the music he listens to, can be compared with the image of the reader depicted by Proust: ${ }^{8}$ a listener (a reader) who is also an actor of the music (of the literature), made up of a sum of attitudes that are not outside the music, but within the music. And this return of the listener calls forth much else besides: music emerges only in a local context, through different places and means of listening; it presupposes bodily drives and is made in different ways; it relies on the existence of a collective. For, it is not a question, vis-à-vis the autonomy of music, of fashioning an equally autonomous musical subject, in order to take this, in turn, as an analytic object cut off from its historic production; no, the listener himself is also an effect of listening reception, in the same way as is the music. ${ }^{9}$

\section{Rap and Techno: Music Already Inundated with Discourse...}

Starting from the foregoing assumptions, what experiments should be devised for these new kinds of music? Indeed, they pose a particular problem. There are already a great number of social discourses firmly attached to them - youth, revolt, immigration, violence, festivals, drugs, etc. Instead of criticizing and reformulating this critical commentary in our account, we tried to show the way in which rap and techno could present 'themselves'. Rather than pretending to determine the meaning and the contents of the music in line with

\footnotetext{
${ }^{5}$ J. Goody, La raison graphique: La domestication de la pensée sauvage (Paris, 1979). For a musicological critique of the privilege accorded to the score. See Joseph Kerman, Contemplating Music: Challenges to Musicology (Cambridge, MA, 1985), and on the particular difficulties of the scholarly analysis of popular music, see Richard Middleton, Studying Popular Music (Milton Keynes: Open University Press, 1990).

${ }^{6}$ Mary Sue Morrow, Concert Life in Haydn's Vienna: Aspects of a Developing Musical and Social Institution (Stuyvesant, NY, 1989); James H. Johnson, Listening in Paris: A Cultural History (Berkeley, 1995); and William Weber, 'Did People Listen in the 18th Century?', Early Music (November 1997): $678-91$.

${ }^{7}$ As is the case with Tia DeNora's approach: "Music as a Technology of the Self", Poetics, 26 (1999): 1-26; and Music in Everyday Life (Cambridge, 2000).

${ }^{8}$ In 'Sur la lecture' ['On Reading'], Preface to Sésame et les Lys [Sesame and Lilies] by John Ruskin, trans. Marcel Proust (Paris, 1987).

${ }^{9}$ On reading, which occupies in relation to the book a position very analogous to that of listening for music, we have been inspired by numerous arguments in the work of Roger Chartier; see Lecture et lecteurs dans la France d'Ancien Régime (Paris: Seuil, 1987); and his edited anthology Pratiques de la lecture (Paris, 1993); see also Hennion, 'L'Ecoute à la question', and Antoine Hennion, 'Listen!', Music and Arts in Action, 1/1 (2008): 39-45;

$<$ http://musicandartsinaction.net/index.php/maia/article/view/listen $>$.
} 
such and such a discipline, it was more a practical matter of seeing how various elements combine and co-construct themselves - the discursive and the gestural, the somatic and the musical, the scenic and the ideological (particularly according to issues recurrently raised by those musical genres, such as gender, violence, the media) - and how these 'make' rap or techno. In this way, we were merely extending the seminar's general methodology: each meeting was to begin with situations where the music is played, heard, interpreted and commented on, in order to study the way that the pairing 'music-fan' is animated through the critical activity of 'listeners' themselves, when, starting from past experience that is not shared equally, they discuss between themselves, compare, reconsider their first impressions, return to other experiences, relativize the conditions of the present listening, or correct previous opinions, etc.

This time, the idea behind the experiment was to reap benefit from the ambivalent relations between rap and techno, from their proximity and opposition, and to organize a comparative demonstration: to present these musics, to put them to the listening test, to show their way of functioning, what they hold of interest, the debates that they arouse. And not doing so from the outside, having recourse to musical and social characteristics aimed at objectifying them (musicological descriptions, origins and history, social background, media reports and current success, etc), but, in conformity with the seminar's ground rules, on the basis of how they are listened to and how they are presented by fans, so as to try to understand how and for whom they 'make music'.

One argument maintains that there is an important and arbitrary distance between the musical elements of rap or techno and the social meanings and practices that are grafted onto these musical genres. Another runs contrary to this, claiming that the former is strongly determined by the latter. Only experiment can cast light on the respective merits of these positions, or perhaps reveal a variety of situations and evolutions. This is how the idea originated that we ought to look at both the music that is made and the music that is spoken about: sounds and contexts. By controlling the conditions of the experiment, the registers that are mobilized to present the interest shown in a particular form of a music are left open, and no attempt is made to solve a priori the question of the existence and solidity of the relationship between one and the other. Another way of describing our aims is: to evaluate simultaneously, in reciprocal fashion, music and the criteria of its perception; to resist choosing between music and words, and, instead, to let the musical and social characters of rap and techno emerge together; to discover what the relevant features of these genres are for their followers, to feel what it is they hold, to perceive more easily how they lend themselves to the construction of differences and formulation of judgements, and more generally to understand how they attach their publics to themselves. Lastly, there is an intention to examine the connections, more or less necessary, that these genres establish between the musical products themselves and the comments to which they give rise.

The meeting takes place in a room of the Bibliothèque Nationale de France equipped with a comprehensive sound system, and a technician also present. The two members of the seminar who volunteered to present 'their' music are both free to conceive and organize their presentations how they wish, and make full use of their access to this equipment. Members of the seminar gather their friends to act as a public, and we total about thirty in the room. We first approach rap, then techno, and we then link them together afterwards in a general debate about what has taken place.

\section{Rap: Music or Revolt?}


Within the framework given, Pierre, who has put together a presentation on rap (or of rap...), chooses to offer his contribution to the sociology of musical genres by exploring how playing and listening to musical excerpts might change the character of an academic argument: what is it that listening alone is able to render comprehensible?

I should like it to be the music that makes us speak rather than the reverse (the sociologist would usually wish to say something concerning the music). I hope that the pieces I've chosen will make the audience react, while I will arrange the recorded titles a bit like a DJ, in accordance with his own reactions...

The idea is to approach as closely as possible the ordinary, commonplace conditions of listening - leaving aside the oddity of this room as an environment for rap. To be strictly accurate, therefore, it is not about putting on a show: there are no vinyl records, sampler, computer, or microphone, only simple CDs and cassettes, the most common supports of rap appreciation (along with radio broadcasts, some of which Pierre had recorded on cassette). Pierre specifies, finally, that he is a researcher, and that the problem is not whether or not he is huge fan of rap: "I am not trying to convince anyone of the "quality" of the music...'

The first song, 'Touche pas à ma musique' ('Don't Touch My Music'), speaks, itself, about the relationship between words, music and origins - 'ma clique' (my crew [gang]) and of the relationships of the rapper with the media and the public; it highlights the difficulty of not privileging voice and text in the analysis of this production. Pierre points out that fans act similarly; they read the lyrics in the booklet, and the dedications and other 'messages to Allah', before listening to the CD they have just bought. The photographs, the garish logos and graphics, also influence their listening. The listener would also do well not to disregard the device of self-presentation with which the singers unceasingly make play: scenes of studio activity and what the rapper does in life, obsession with realities, constant references to social background, and continual demands that listeners 'open their eyes' to the world. Another characteristic of rap is to play with this intricate web of enunciations and reminders of the context of these enunciations on the disc itself: the presence of intros, outros, and other interludes which are inserted among the pieces, made up of played scenes, studio outtakes, telephone conversations; these are all means of ensuring the rapper reappears in the context of his production, and are often present also, as Pierre says, 'to reinforce a social layer'. Rap is not detached from the rapper, the production forms part of the product. In a symmetrical way, among fans, the same applies to 'promo' clips, which are always accompanied with abundant notes: they re-forge the link between the music, the rapper, and the social message of rap. The common practice of fans never ceases to show that they themselves privilege these aspects, and they associate them, above all, as values that have come out of what they consider rap. A rapper like MC Solaar, for example, is criticized for the distance he has moved from his social origins, rather than for his music; he is regarded as having become too integrated.

Pierre tries to choose titles from a great variety of styles to counter the current gibe, 'rap, it's always the same' ('Staying Alive' by Wyclef Jean, an American rapper labelled more 'commercial', a production starting out with a well-known 'sample' of the Bee Gees; Wu Tang Clan, a celebrated New York group with a dark and tortured sound; an excerpt from two contrasted albums by Stomy Bugsy; and two deliberately very different songs from the same album by NTM, ${ }^{10}$ 'La Fièvre' and 'Paris sous les bombes'). The audience comments most of all, in rather crude terms, on the moods that the pieces unleash: harder or more

10 'Nique ta mère' ('fuck your mother'), one of the first famous rap groups in France. 
festive, darker or more dancing... The rhythm and tempo sometimes seem more stereotyped, sometimes more unusual or studied. Lastly, the manner of declamation, the accents and use of the voice take us back to what seems to be the most salient element of the genre, speech-song.

In the discussion, which opens up little by little, participants suggest that the rather stable character of the resonant background, once the piece began, invite few remarks, whereas the words call automatically for social commentary. The same goes for rapping: to what extent is it really possible to vary it? Is this not typically the trick, the key feature whose success certainly gave rap its strong image, but also brings the danger, as in the case of punk or pure and hard rockabilly, that such an over-rigid process can be captive to a binary choice: either you obey it (although it is very determining and constraining) and you rap, or you free yourself of it, you twist it, you shift, but almost immediately you do so, you are no longer rapping.

From here, questions slip inexorably towards two topics, in spite of the efforts of Pierre who tries to retain everyone's focus on the precise sound aspects of the songs: on one side, the mode of production, the social context of the rappers, and on the other the content of the words and, more particularly, their social import. The problem, also, is that the object leaves us no choice. The desire to determine it externally, outside its own criteria, does not lead to the revelation of a level that is usually invisible or latent. It just misses the specific space where arrangements, variations, and relevant connections come together, that space to which we are sent back constantly when following up the sayings and doings of actors, musicians as much as consumers or commentators. Pierre is led to explain the way in which rappers work, the origin of the 'samples' and, more generally, the relations that allow the social milieu of rap to function, the DJ market, the origins of the movement in the United States and in France. But he is reticent: all this can be found in the literature that has multiplied on the subject of rap. ${ }^{11}$ The debate becomes animated around the greater or lesser degrees of 'gangsterism' found in this milieu and the type of relations that reign there: clans, mafia-like godfathers, influence and threats, machismo, the rule of money and of bragging... In which part they are real, and simply overplaying the myth - in a symbolic inversion of the dominant order, as sociologists might say. What are the practical consequences, in everyday reality, of this aggressive behaviour, even if it is in large part provocation and ostentation?

The room reacts in particular to the violence, racism or sexism of certain words, comparing these features with those of earlier movements such as rock 'n' roll or punk, while trying to decide if they are irony or provocation, and insisting that these are not simply the same things in all cases. Several speakers considered, for example, that the use of Nazi insignia by punks, or the satanic imagery of hard rock, was more a means of displaying excess and of dramatizing their gestures of provocation, whereas the macho violence of rappers seems closer to the reality of their practices. But the positions are not distinctly taken: there is a feeling that it is difficult, where this topic is concerned, not to fall into well-worn debates of this kind, so everyone maintains a highly questioning stance.

\footnotetext{
${ }^{11}$ Among the best-informed French texts are the following, rather arbitrarily selected from a now abundant field: George Lapassade and Philippe Rousselot, Le Rap ou la fureur de dire (Paris, 1990); S.B.G. Desse, Freestyle (Paris, 1993); Hugues Bazin, La Culture hip hop (Paris, 1995); O. Cachin, L'Offensive rap (Paris, 1996); José-Louis Bocquet and Philippe Pierre-Adolphe, Rap ta France (Paris, 1997); Manuel Boucher, Rap expression des lascars: significations et enjeux du rap dans la société française (Paris, 1998); Christian Béthune, Le Rap: une esthétique hors la loi (Paris, 1999); E. Grynzpan, Bruyante Techno (Nantes, 1999); S. H. Fernando Jr., The New Beats: culture, musique et attitudes du hip hop (Paris, 2000); and 'Territoires du hip hop', Art Press, Hors Série (December 2000).
} 
This method is no less effective for that. It allows two current questions, often hostile to the genre, to be stated and discussed together: does rap reflect (at best) or reinforce (at worst) youth violence? Is it not, at the same time, a commercial and mediatized music, completely integrated, so that its provocative character, far from constituting a revolt and a challenge to 'society', helps it above all else to sell (a question posed in similar terms in connection with the Rolling Stones in the early days of rock 'n' roll)? Moving in another direction, a condescending complacency is identified and criticized, one that would excuse rap of any moral or political responsibility in the name of the social and ethnic origins of its actors: one cannot, without going to extremes, use this as an excuse for regarding an insulting and aggressive vocabulary as merely a matter of choice of style, something neutral or unimportant on the political, human, or moral level, and without effect on individuals or communities.

\section{Techno: Grasping the Sound}

Paul, for techno, took a resolutely different approach. For him, showing is doing. He arrived with two friends, one of whom is a DJ, and all their hardware, in particular their metal bags filled with vinyl discs. In front of the two turntables, installed with the help of the technician, they provide a brief history of the origins and the various types of techno. The room quickly stifles its questions about the reality of events or filiations, the alternatives to this account, its mythological character, its grey areas: we understand that there will be no chatting about these. That is not what it is about. This 'history' is that of a young collectivity rewriting itself in real time. It furnishes techno with some worthy ancestors such as Pierre Henry, Tangerine Dream and Kraftwerk, and if this mythology is extended, Schaeffer, Russolo, Stockhausen... It retraces techno's origins to key moments and founding places, already so familiar: Jamaicains in New York, garages in New Jersey, English dance clubs, the French disco DJs that preceded them. It is myth in the strong sense, a performative history: a genre is created in front of us through the story it tells of itself.

In the same way, the succinct presentation of the principles of production and the hardware required ('kick', beat boxes, samplers, MIDI sequencer), followed by a classification of the types of techno presented by their English names and their tempo ('bpm' or beats per minute), leaves us with the impression of a catalogue. Can a genre be adequately defined with reference only to a certain number of drumbeats per minute? From trance, at between 125 and $140 \mathrm{bpm}$, and tribal techno, one goes up and up, passing by 'acid core' in the neighbourhood of 150-160, then 'gabber' and hard-techno, until we reach 'hard core' at 180-250, but which, we are told proudly, can go up to $300 \mathrm{bpm}$... We assume that it is not a matter of analysis but, rather, a verbal characterization, and it will be more a question of measuring its appropriateness and effectiveness than engaging in discussion. In fact, it is an introduction to this world, a guide to places, and a lexicon of the names of the various components of these sub-genres. This brief account leads on to a rapid characterization of 'hard core', the genre that Paul and his associate champion, and are now going to illustrate.

They play several discs, as for a mini-set, and show us the principal forms of DJ intervention, how vinyl discs are chosen, the use of headphones and techniques for handling decks in order to superimpose and connect discs, and how they conceive their temporal mode of working as being similar to 'telling a story'. ${ }^{12}$ They call some people to

\footnotetext{
${ }^{12}$ Morgan Jouvenet, “Emportés par le mix": les DJ et le travail de l'émotion', Terrain, 37 (September 2001): 45-60.
} 
the front to have a go at handling the consoles and at coordinating their movements so as to mix sounds and alter speeds ('mixes' and 'scratches'). They discuss with us the tricky moments that the DJ encounters, and whether or not these mistakes are perceived by those in the know, or by us: blank spaces, ruptures, feelings of missed transitions, an overall mood that is awkward to assess.

The opposing strategies adopted by Pierre and Paul are seen in every detail of their two demonstrations: Pierre's warning not to take him for a rapper is answered by Paul's personal image, his shaven head and posture indicating clearly: 'I am one of them!' The analytical effort of the first is answered by the hip vocabulary of the second, which for the uninitiated resembles a code. The effort to objectify and set apart is countered by teaching by example - 'see it and do it yourself' - and the imitative seduction that witnessing a passionate interest arouses. Pierre even started debates he wanted to avoid - but these verbal skids clearly reveal rap's constitutional character. Paul creates the desire on our part (at least temporarily) to share in and to live the object that his presence and gestures conjure up before us and among us - at the same time as he forces us to delay any effort to analyze what comes out of this.

And, indeed, as soon as Paul and his friend go into action, the nature of the scene changes. They invested a great deal of themselves in the meeting, and thought meticulously about their discs. They put body and soul into it. The very institutional character of the place acted as a challenge to these underground musicians, who were excited with the idea of dynamiting the interior of such a temple (and, perhaps, the normal procedure of the seminar, too), in 'making the BNF collapse under the kil[owatt]s' (even if, as a concession to our eardrums, they officiate with a tenth of the power of some sound systems). The effect is powerful, and several among us comment on it in various ways: the issue is no longer that of wondering whether or not this music is liked, which would be too much the question of an outsider, but of seeing it actually being made, feeling those moments that are more or less successful, following the variations, recognizing the variables on which the DJ works, the more or less reverberant or dry timbres, the density of texture, the continuity of sound, its ruptures and restitutions, the more or less intense or relaxed moments, etc.

It is an important lesson, one that relates to the communicative effect of practice - the mimetic force of doing compared to saying - but even more so to the multiplicity of possible registers of participation in a musical experiment. Indeed, it is all about the continuity of these positions, rather than a binary opposition between those who would be fans and participants, and those who would be non-fans and distant: we did not become fans of techno, losing at a stroke all critical sense, renouncing any analysis in the pleasure taken. No, thanks to the mediation of a new system, we simply went through a series of intermediate positions together. We allowed ourselves a kind of delight by proxy, which engaged us truly, though only for a limited time and place, in the position of the fan. Even the production of this 'us', with its provisional and fragile status, is an effect of the meeting. As one among us says, 'the principal result of the meeting for me will not be to make me like techno more on a personal level, but to understand that it can be liked'. While it is being played, we are sensitive to the work on 'samples', to this emphasis on over-exploiting a dimension of sound - work that, after all, very much resembles that which, employing more diverse parameters (from the sounds of natural instruments to the voice, from polyphony to rhythmic devices), can be found in many musical practices that pre-date techno.

A specific point seems to hold in the technical production of this music: there is no distance between the gesture that makes the music and the music that is made. Admittedly, to a certain extent, sight supports sound this way in any performance: watching executants 
is helpful when paying attention to their artistic technique. It is said, in fact, that spectators themselves play a little, too, by making imitative gestures with their bodies, such as swaying to the rhythm of the music they hear being played. However, the gap between the gesture made on an instrument and the music that is produced remains important. The visual and sonorous references coincide on secondary parameters (rhythm, intensity...), rarely on melody and harmony, which cannot be 'seen' so directly. There is, by contrast, a striking immediacy between the gestures of the DJ and the sonorous effect produced: the speed shifting of discs, the move from one disc to another, the rise or fall of the volume, all is heard immediately. Techno operates through the manipulation of music already made, and this interval in which the pre-existing material becomes transformed and mixed has, as a curious consequence, an extreme legibility, an easy and instantaneous passage between gesture and sound that helps it to be perceived very clearly.

We wonder if the rule that requires DJs to be invisible on techno nights and, instead of being positioned as instrumentalists, to officiate without being seen, is not a means of compensating for this excessive visibility of their actions; the device of having music diffused by the sound system and coming from who knows where, accords with this idea, and is perhaps, in this second form, aimed at giving dancers another interpretation of the music, one suggestive of interior vagueness, of something lacking a place in which to show itself. Within the framework of our meeting, this visual element contributed strongly to the success of the experiment. For music such as this, which merges with the gestures of its own making, to show is to explain: the tactic adopted was perfectly adapted to that end. We even relativize our initial doubts regarding the definition of sub-genres of techno by their tempo alone: in practice, it is striking to see how far this aspect - the work on a throbbing 'boom-boom', and on the very mechanics of the rhythmic repetition of an evolving sound - is, in effect, largely determined by tempo.

\section{Sociology 'of' Techno, Sociology 'of' Rap}

The concluding discussion relates to social milieu, the sociality of techno fans, the market forms of this music: the disc is its original material (the DJ's vinyl) at the same time as it is one of the end products; but a good share of techno reality breaks free of the recording in much the same way as it does from orthodox visual media - that said, and more, it is also listened to at home and is sold in the form of commercial recordings. Finally, if a part of the activity is semi-clandestine and displays an underground and anti-commercial character, the other part could not be more overt, installed, as it is, in the world of nightclubs, and subject to the strong internal divisions carved out in a predictable manner among enthusiasts for this dance music and followers of rave parties.

From here, of course, the debate could bounce back and the comparison with rap recommence. It seems that the sociology of techno is played out elsewhere, in a form somewhat removed from the classical opposition between a 'pure' origin and the commercial success to which rap aspires, a form that more closely resembles that of avantgarde or 'underground' movements: the development of a common taste and practice gradually produces the new identity of a group, then around it, if this is successful, a 'generation' arises, produced and expressed in that same gesture. It is on location, while going to the clubs, the dance nights, and the rave parties, that, in line with ethnological practice (and in the manner achieved by works on rock by Frith or Hebdige thirty years earlier) one will begin to 'feel' one's way towards a sociology of techno, beginning from its capacity to engender a collective.

In the case of rap, there is constant reference to life style, to 'social problems' (misery and injustice, affairs and scandals...), to imaginary universe of the media rappers are part 
of (animated drawings, gangster or kung-fu films, TV news...), or to the record market and television networks. This is a long way from the usual split between musicians who take a purely musical view of their production and sociologists who come along to reveal what truly determines it (despite the resistance that producers and fans are supposed to marshal against such revelations): here, instead, it is the producers who ensure that sociology is at the forefront in registering the manufacture and interpretation of their music. This is what makes the sociology of rap problematic: the comments made by specialists give the impression of merely repeating - in a heavier fashion and with too much seriousness - the analyses of rappers themselves. The sociologist, being used to dealing with the aesthetic opinions and blithely anti-sociological comments of fans, is caught on the back foot by an explicitly sociological discourse. His discipline has become a central resource of the actors he observes, and his own analyses compete with theirs: the sociology 'of' rap is, at the same time, something that rap itself puts to work, and what sociologists make of it.

Finally, in this context, and in a symmetrical way, the question of the sociologist's own tastes weighs once more upon him: 'Hey you! Aren't you a bit of a fan, too? What drives you to write on the sociology of this music?' It is not that being reflexive implies that you can only study what you like, and that yesterday's prohibition should become today's imperative (the sociologist engaging his tastes in his work, instead of making an abstraction of his 'subjectivity' and adopting a pose of benevolent neutrality), but an account of how the analyst relates musically to the music that is being analyzed ought to be added to the analysis as another level of reflexivity, one bearing on the tastes and reactions of the sociologist, and showing how he is affected by what he hears in the capacity of listener or fan.

\section{Conclusion: Towards Reflexivity, Reflexivity and More...}

When compared, the two methods of presentation can be seen as putting to the test the tacit assumptions that each presenter held about the music they were dealing with: the first envisaged it as an object captured on tape, ready to be dissected; the second thought that the only way to put the music across was to produce it live, trusting in the gestures it made and the sonic events it propelled into being. It was a choice crowned with success, at least in the local circumstances provided by our comparative exercise. The fact that Paul hardly speaks does not mean that his activity does not 'speak'. It speaks because, even without words (or almost without), he shows how the activity relates to itself in the course of its realization. Through his hardware, his gestures, his attentiveness to our reactions, his effort to make the progressive and hesitant production of a sound world emerge before us and within us, Paul presents his music to us by offering us a grasp of something the noninitiated can seize for themselves. In response to his work, we do not take a distant and objective stance but, rather, our bodies are engaged in the experiment, the body being one of the experiment's variables in two meanings of the term: a changing element, not fixed or given, and one with reactions to be measured. 'Seek out the reflexive, the reflexive and more!'

The method we had imagined - music to be heard, music to be seen - was completely redundant in the case of techno and, in contrast, incoherent when it came to rap. Rap is full of demands, of setting in context, of provocation, and these social registers call for a response or reaction that quite naturally maps itself around the same issues. The last and most important level of reflexivity is revealed here: ${ }^{13}$ music is not an inert object, but

\footnotetext{
${ }^{13}$ Anoine Hennion, 'Those Things That Hold Us Together: Taste and Sociology', Cultural Sociology, 1/1, ed. D. Inglis, R. Wagner-Pacifici (2007): 97-114.
} 
rather an animated project that already proposes its own interpretations. It calls for certain reactions, and often constructs and evolves itself as a genre as a result of those reactions. It is for that reason that a genre's history becomes part of the genre itself; it participates in the collective work to isolate relevant features and to characterize what needs to be done. This it achieves even if it means some features become solidified, either musically, as over-rigid formulas (following the tendency of music that is easy to identify but difficult to revitalize, such as the tango and rockabilly mentioned earlier), or socially, as is the danger with rap, resulting in a 'posture' of revolt or a quickly stereotyped social gesture, even if the desire was to be seen as a protester.

These elements can be linked to musical features, but also to much else besides: to ways of doing things or being together, to practices or ritualized signs, to age groups and various social or ethnic identities. It is not for us to sort them out. A very particular analytical interest concerning these present-day musical styles comes precisely from the coconstruction of these features among themselves. Their contemporary character enables us to assist in this process 'live', before music history solidifies them into musical genres. Analysis consists partly of recognizing these criteria, rather than imposing criteria from without.

It is thus that, ultimately, this double meeting invited us to participate in a lesson on reflexivity. There is no middle-of-the-road position in this matter. The sociologist may feel able to take his leave, discrediting the spontaneous sociologies of the actors he has observed, and emphasizing the distance between his own critical and scientific analyses and their partial and interested accounts, but we would argue that he does not actually 'leave' at all. On the contrary, he dives right into the problem: he accepts the need to take issue with the totality of accounts given about a certain type of music, his own included. This is not to say that he abandons all critical direction when situating himself among and playing with this mass of lay opinion, but, instead, that he goes along with all the little differences of perception, which may be described as the variable series of effects and adjustments that the friction of reflexivities involves. This ranges from his own questions, as a sociologist, about what is occurring before him and in him (as much sensory as cognitive), to the words of actors who, far from lacking categories in which to think their practice, do not differentiate between musical activity in itself and the activity of drawing a framework around it. ${ }^{14}$

\footnotetext{
${ }^{14}$ It is clear that the concept owes much to ethnomethodology; see Harold Garfinkel, Studies in Ethnomethodology (Englewood Cliffs, 1967). For classical presentations of what is at stake in reflexivity, see James Clifford et George E. Marcus (eds), Writing Culture: The Poetics and Politics of Ethnography (Berkeley, 1986); Steve Woolgar, Knowledge and Reflexivity (London, 1988) (1988); Malcolm Ashmore, The Reflexive Thesis: Wrighting [sic] Sociology of Scientific Knowledge (Chicago, 1989); and Ulich Beck et al., Reflexive Modernization (Cambridge, 1994).
} 